\title{
A perspective on land sparing versus land sharing
}

\author{
Anna Renwick and Nancy Schellhorn
}

\section{Key lessons}

- Agri-environment schemes have the potential to increase biodiversity in productive landscapes.

- The land sparing/land sharing framework uses trade-offs between agricultural yield and biodiversity to choose between two ways of achieving biodiversity conservation in agricultural landscapes, but its simplicity has generated considerable debate.

- Land sharing and land sparing represent a false dichotomy. Strategies for biodiversity conservation in agro-ecosystems form a continuum between these two extremes.

- Using different measures of diversity, considering the appropriate scale, and incorporating land use history and social factors will enable more robust management decisions to be made which best support biodiversity and production in agro-ecosystems.

- Addressing these gaps in the current production/biodiversity trade-off will enable more efficient management plans to be implemented which are directly applicable for the design of agri-environment schemes. 


\section{Introduction}

Loss of biodiversity in agricultural landscapes is an important issue in conservation biology. Simultaneously, there is much concern over the ability to produce sufficient food to feed the growing global human population. There is often a disparity in the agendas of agriculturists and conservationists, with the former focusing on increasing production, often to the detriment of the environment, and the latter focusing on biodiversity conservation, with little interest in increasing food production (Foley et al. 2011). Agri-environment schemes, where farmers are paid through agri-environment subsidies to manage land primarily for wildlife, have been implemented in an attempt to conserve and prevent further declines in biodiversity on farmland. However, the effectiveness of these schemes, in terms of biodiversity conservation, has been questioned (Kleijn et al. 2011). They may also lead to reductions in crop yield (Kaphengst et al. 2010).

Scientists are currently trying to address the disparity between production and biodiversity by analysing trade-offs between agricultural yield and biodiversity conservation (Green et al. 2005; Phalan et al. 2011; Hulme et al. 2013), called Land Sharing Land Sparing (LSLS). Under this approach, land use is categorised as:

- Land sparing: the intensification of production to maximise agricultural yield within a fixed area and dedicating other land to biodiversity conservation; or

- Land sharing (also called 'wildlife-friendly farming', such as that seen within the agri-environment schemes): the aim here is to maintain biodiversity within less intensively farmed agricultural landscapes.

This conceptual framework has stimulated considerable debate, with many arguments supporting both LSLS strategies (Fischer et al. 2008; Tscharntke et al. 2012; Fischer et al. 2014; von Wehrden et al. 2014). In this chapter, we provide a perspective on the main issues of LSLS that cause debate and suggest potential improvements in evaluating the best management strategy for successfully protecting biodiversity without compromising production. Our aim is to help guide the design of future agri-environment schemes. 


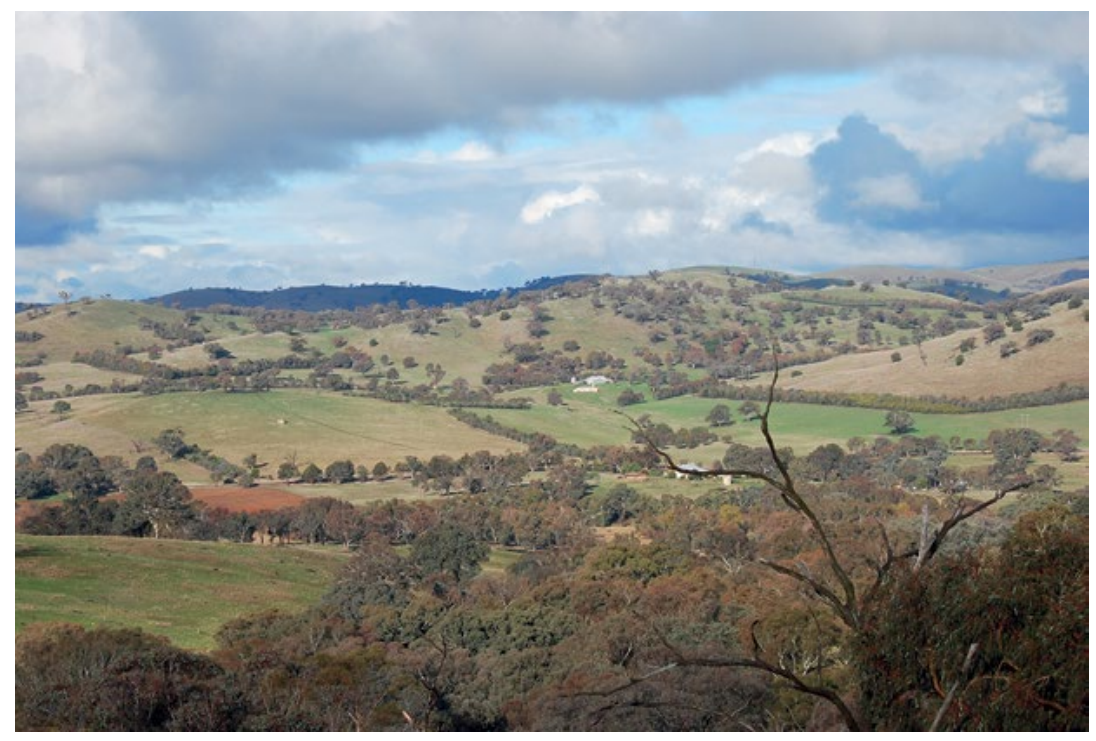

Figure 9.1: An example of land sharing in southern Australia, illustrating the coexistence of agriculture and biodiversity. Source: Photo by Dean Ansell.

\section{Issues causing debate in the LSLS framework}

\section{LSLS is a false dichotomy}

The LSLS framework categorises agricultural land as one of two extremes. However, in reality there is a need to spare land from agriculture (e.g. areas of high biodiversity value and endemism), protect high value agricultural land, and identify interventions on agricultural land that will support biodiversity and contribute to ecosystem services. Agri-environment schemes typically fit into the last category. Biodiversity, such as native insect pests, pollinators, and below ground invertebrates, underpins a wide variety of ecological goods and services which contribute to agricultural productivity. Some production systems and landscapes may have the opportunity to capture many of the ecosystem services provided by biodiversity, such as pollination (Aizen et al. 2009) and pest control (Crowder et al. 2010), while other systems are more constrained to artificial inputs, 
such as fertiliser and lime. The issue is not whether we should spare or share land, but rather the need to identify opportunities to increase agricultural production while minimising the negative impacts on the environment and stemming further biodiversity loss - for example, managing ecosystem services in agricultural landscapes to maintain or enhance yield level rather than relying on external inputs (Bommarco et al. 2013).

\section{Efficient allocation of land}

Recent articles using the LSLS framework attempt to frame the central point of interest as food security or food production (e.g. Phalan et al. 2011; Hulme et al. 2013), however, their focus can more appropriately be described as the most efficient allocation of land. This mismatched claim has attracted considerable criticism, as food security is a much more complex concept than the simple amount of food that is produced, and agricultural landscapes are often used for much more than food production (e.g. biofuels and fibre), which needs to be considered when managing landscapes (Fischer et al. 2014). This land allocation question is central to agri-environment schemes: how much land should be designated to production and how much to protecting biodiversity, in addition to the spatial arrangement of these activities?

\section{Biodiversity in agro-ecosystems}

Different taxa respond differently to changing land use and processes, and the response by species at a plot or field level may be very different from the response seen across landscape scales. Extrapolating across species groups and various scales commonly produces misleading results. This has been seen in the current agri-environment schemes, where targeting management to preserve one species may not provide a solution for other aspects of biodiversity (Kleijn et al. 2011). Additional measures of diversity are therefore needed to ensure actions support a multitude of species rather than just a single species. Von Wehrden et al. (2014) propose measuring beta and gamma diversities instead of simply alpha diversity to better capture the landscape scale variance in biodiversity in relation to land use changes. 
9. A PERSPECTIVE ON LAND SPARING VERSUS LAND SHARING

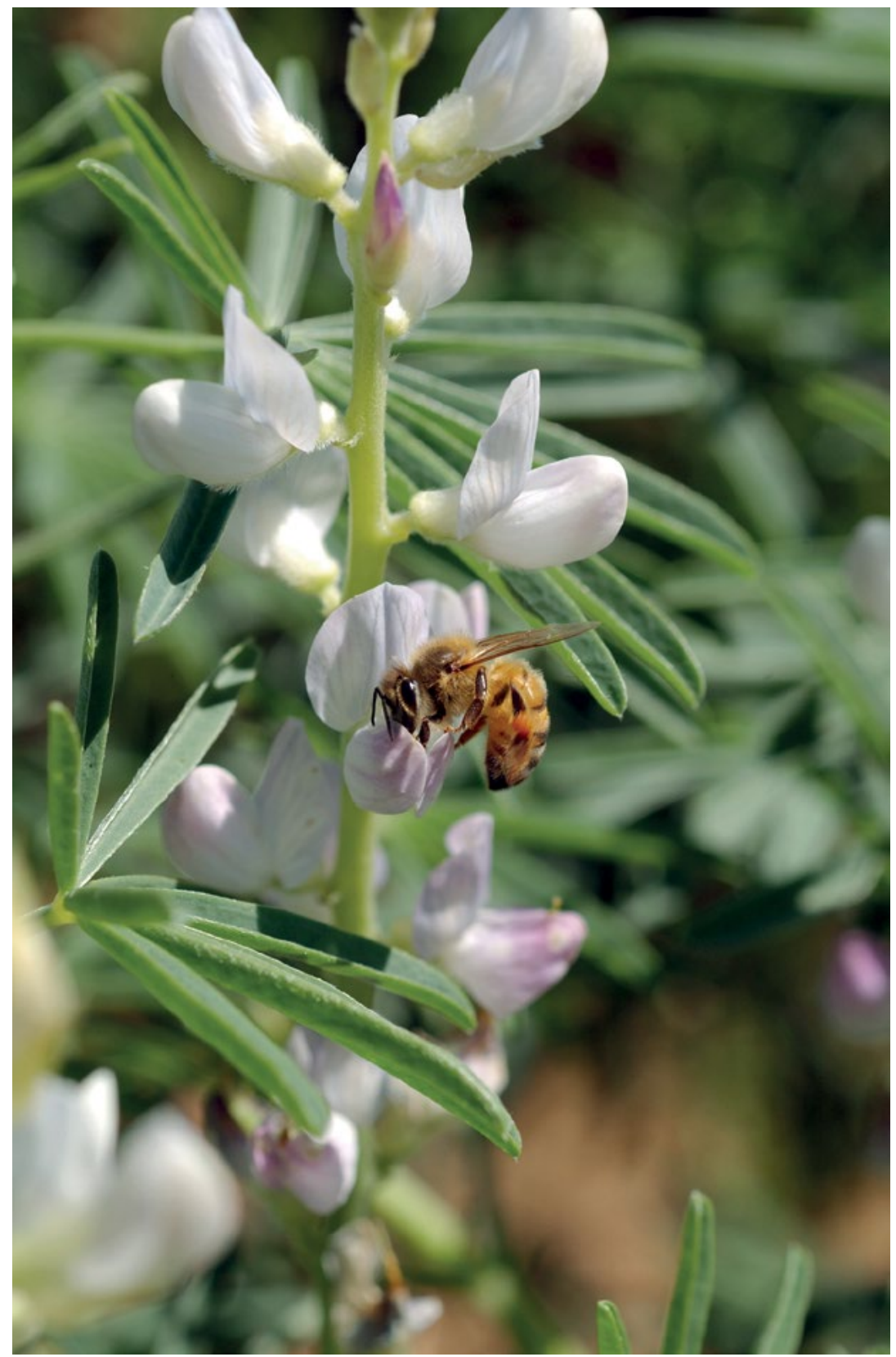

Figure 9.2: A bee pollinating a lupin flower on a farm in western NSW.

Source: Photo by Carl Davies (CC BY 3.0). 


\section{Scale, landscape composition and leakage}

Opportunities identified to increase production from intensification need to explicitly consider scale. This will help identify the appropriate study and management scale. Many biodiversity-yield interactions are affected by the scale and composition of the landscape, yet the LSLS framework does not incorporate scale, which can lead to confusion when trying to determine appropriate management. In addition, land use is often driven by distant drivers, such as global markets, and actions taken at the farm or regional scale can impact areas further afield. This leakage affect is rarely, if ever, considered, yet can have large impacts globally, making it an additional aspect to factor in when making land use decisions, including the operation of national agri-environment schemes (Renwick et al. 2015).

\section{Land use history}

Knowing the historical context of land use can influence the current pattern of biodiversity and appropriate management. Most studies present a snapshot in time, failing to account for the history of the landscape, despite land use history having a key influence on current species diversity and land use (von Wehrden et al. 2014). The key to determining the optimum land use strategy for a landscape depends largely on if it is a frontier landscape, where primary habitat is under pressure from agriculture - for example, in northern Australia and areas of Brazil - or a traditional landscape, where farming has been carried out for centuries. Biodiversity in traditional farming landscapes tends to be concentrated in specific areas such as remnant native vegetation and plantings (e.g. shelter belts). Protection of these areas is essential. However, they are also prime target areas for conversion under intensification. In contrast, in frontier landscapes, biodiversity is more evenly distributed across the landscape and the effect of intensification is more uniform across the landscape. Land sparing may be possible in frontier landscapes, whereas land sharing is most likely in the former (von Wehrden et al. 2014). 


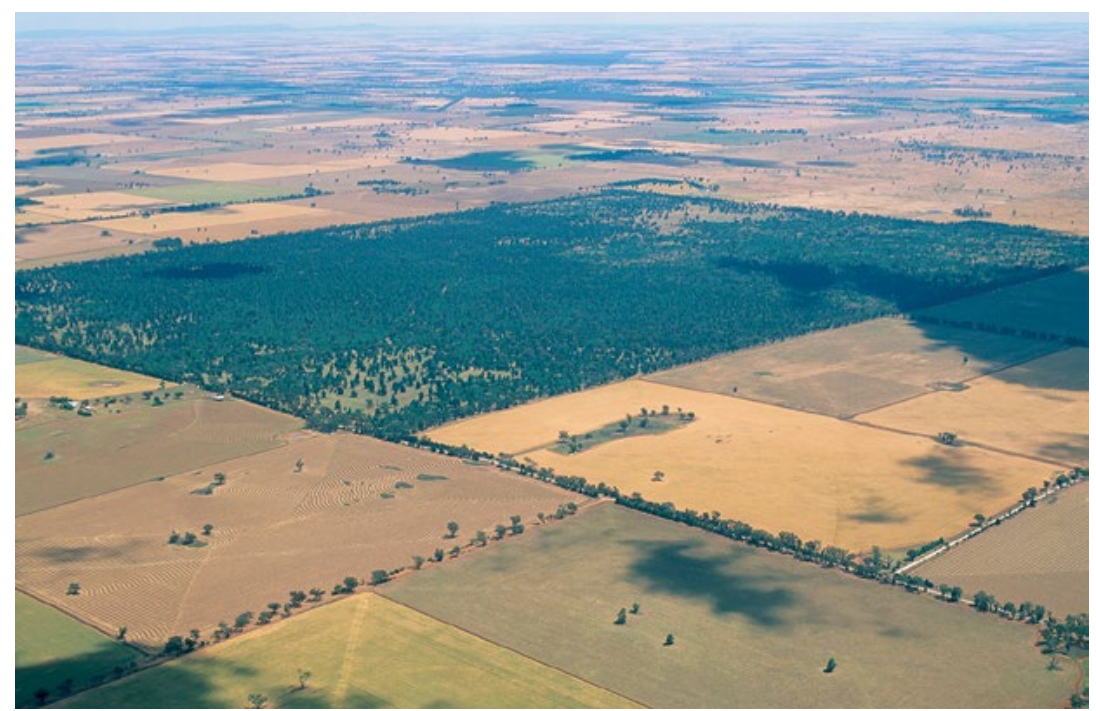

Figure 9.3: Remnant vegetation surrounded by wheat crops in New South Wales, demonstrating a land sparing approach. Agriculture is intensified into areas separate from those specific for nature.

Source: Photo by Gregory Heath (CC BY 3.0).

\section{Social values}

Social values are unaccounted for in the LSLS framework. The disconnect between people and nature is often cited as a prime reason for a decline in biodiversity (Fischer et al. 2014). Both land sparing and land sharing may encourage the connection between nature and people, but in different ways (wild nature in protected areas, or tamer nature within farms themselves). Despite the relevance of this observation, to date no data on these social elements have so far been incorporated to the LSLS framework. Incorporating social values is essential to achieving successful conservation actions, whether land sparing or sharing is identified as being the best management option. Some actions within agri-environment schemes have social as well as conservation value - for example, hedges. Identifying measures to incorporate this in evaluating their overall value is essential. 


\section{Conclusion}

Identifying the most appropriate land use management is clearly imperative for protecting biodiversity in agricultural landscapes. The LSLS framework has identified some of the major challenges and highly contested aspects of land use. However, by limiting land use decisions to two options at either of end of the intensity spectrum, the framework omits to consider land use between the extremes. Agri-environment schemes may be considered a land sparing approach, but determining how these should be designed and implemented is imperative. Here we have identified some gaps in the LSLS framework that still need to be addressed, and suggested the data that is needed to fill these gaps to enable solutions to be found. Addressing the above points will enable a more robust analysis and the development of a successful land management strategy (e.g. agri-environment scheme) to be implemented in agricultural landscapes where biodiversity can be better protected with minimal if any compromise on productivity.

\section{References}

Aizen, M.A. and L.D. Harder (2009) 'The global stock of domesticated honey bees is growing slower than agricultural demand for pollination', Current Biology 19(11): 915-18.

Bommarco, R., D. Kleijn and S.G. Potts(2013) 'Ecological intensification: Harnessing ecosystem services for food security', Trends in Ecology and Evolution 28(4): 230-8.

Crowder, D.W., T.D. Northfield, M.R. Strand and W.E. Snyder (2010) 'Organic agriculture promotes evenness and natural pest control', Nature 466: 109-12.

Fischer, J., D.J. Abson, V. Butsic, et al. (2014) 'Land sparing versus land sharing: moving forward', Conservation Letters 7(3): 149-57.

Fischer, J., B. Brosi, G.C. Daily, et al. (2008) ‘Should agricultural policies encourage land sparing or wildlife-friendly farming?', Frontiers in Ecology and the Environment 6: 382-7.

Foley, J.A., N. Ramankutty, K.A. Brauman, et al. (2011) 'Solutions for a cultivated planet', Nature 478: 337-42. 
Green, R.E., S.J. Cornell, J.P.W. Scharlemann and A. Balmford (2005) 'Farming and the fate of wild nature', Science 307: 550-5.

Hulme, M.F., J.A. Vickery, R.E. Green, et al. (2013) 'Conserving the birds of Uganda's banana-coffee arc: Land sparing and land sharing compared', PLOS ONE 8: e54597.

Kaphengst, T., S. Bassi, M. Davis, et al. (2010) Taking into account opportunity costs when assessing costs of biodiversity and ecosystem action, Ecologic Institute, Berlin.

Kleijn, D., M. Rundlof, J. Scheper, et al. (2011) 'Does conservation on farmland contribute to halting the biodiversity decline?', Trends in Ecology and Evolution 26: 474-81.

Phalan, B., M. Onial, A. Balmford and R.E. Green (2011) 'Reconciling food production and biodiversity conservation: Land sharing and land sparing compared', Science 333: 1289-91.

Renwick, A.R., O. Venter and M. Bode (2015) 'Reserves in context: planning for leakage in protected areas'. PLOS ONE 10(6): e0129441.

Tscharntke, T., Y. Clough, T.C. Wanger, et al. (2012) 'Global food security, biodiversity conservation and the future of agricultural intensification', Biological Conservation 151: 53-9.

von Wehrden, H., D.J. Abson, M. Beckmann, et al. (2014) 'Realigning the land-sharing/land-sparing debate to match conservation needs: Considering diversity scales and land-use history', Landscape Ecology, 29(6): 1-8. 
This text is taken from Learning from agri-environment schemes in Australia: Investing in biodiversity and other ecosystem services on farms, edited by Dean Ansell, Fiona Gibson and David Salt, published 2016 by ANU Press, The Australian National University, Canberra, Australia. 